\title{
MODELING THE IMPACT OF SURFACE CHARACTERISTICS ON THE NEAR SURFACE TEMPERATURE LAPSE RATE
}

\author{
M. K. Firozjaei ${ }^{1}$, S. Fathololuomi ${ }^{2}$, S. K. Alavipanah ${ }^{1, *}$, M. Kiavarz ${ }^{1}$, A. Vaezi ${ }^{2}$, A. Biswas ${ }^{3}$, A. Ghorbani ${ }^{4}$ \\ ${ }^{1}$ Dept. of Remote Sensing and GIS, Geography Faculty, University of Tehran, Tehran, Iran - (Mohammad.karimi.f, kiavarzmajid, \\ salavipa)@ut.ac.ir \\ ${ }^{2}$ Dept. of Soil Science, Faculty of Agriculture, University of Zanjan, Iran - (fathololomi.s, vaezi.alireza)@znu.ac.ir \\ ${ }^{3}$ School of Environmental Sciences, University of Guelph, Guelph, Ontario, Canada - biswas@uoguelph.ca \\ ${ }^{4}$ Rangeland and Watershed Management Department, University of Mohaghegh Ardabili, Ardabil, Iran - aghorbani@uma.ac.ir
}

Commission VI, WG VI/4

KEY WORDS: Biophysical Characteristics, Topographic Parameters, Satellite imagery, NSTLR.

\begin{abstract}
:
Modeling of Near-Surface Temperature Lapse Rate (NSTLR) is very important in various environmental applications. The Land Surface Temperature (LST) is influenced by many properties and conditions including surface biophysical and topographic characteristics. Some researches have considered the LST - Digital Elevation Model (DEM) feature space to model NSTLR. However, the influence of detailed surface characteristics is rare. This study investigated the impact of surface characteristics on the LST-DEM feature space for NSTLR modeling. A set of remote sensing data including Landsat 8 images, MODIS products, and surface features including DEM and land use of the Balikhli-Chay on 01/07/2018, 18/08/2018 and 03/09/2018 were collected and used in this study. First, Split Window (SW) algorithm was used to estimate LST, and spectral indices were employed to model surface biophysical characteristics. Owing to the impact of surface biophysical and topographic characteristics on the LST-DEM feature space, the NSTLR was calculated for different classes of surface biophysical characteristics, land use, and solar local incident angle. The modeled NSTLR values based on the LST-DEM feature space on 01/07/2018, 18/08/2018 and 03/09/2018 were 8.5, 1.5 and $2.4{ }^{\circ} \mathrm{C} / \mathrm{Km}$; respectively. The NSTLR in different classes of surface biophysical characteristics, land use type and topographical parameters were variable between 0.5 to $14{ }^{\circ} \mathrm{C} \mathrm{Km}^{-1}$. This clearly showed the dependence of NSTLR on topographic and biophysical conditions. This provides a new way of calculating surface characteristic specific NSTLR.
\end{abstract}

\section{INTRODUCTION}

Temperature Lapse Rate (TLR) is the rate at which temperature changes with elevation in the atmosphere (Kattel et al. 2018; Li et al. 2013). Modeling TLR is very important in various applications including climate studies, soil moisture, hydrology, runoff analysis, energy balance, evapotranspiration, air temperature modeling, and normalization of Land Surface Temperature (LST) (Kattel et al. 2018; Romshoo et al. 2018; Weng et al. 2019).

The value of TLR is not generally constant and should be determined according to the time and geographic locations (Danielson et al. 2003; Minder et al. 2010). In some studies, air temperature recorded in synoptic stations at different altitudes in a region were used for modeling of TLR (Blandford et al. 2008; Rolland 2003). The generalized linear regression is the widely used method to model TLR in a small geographic area based on air temperatures (Kattel et al. 2018).

However, the spatial distribution of synoptic stations to record meteorological and climatic data are generally scarce in many mountainous regions (Firozjaei et al. 2019). Therefore, it is not always possible to model TLR using the traditional methods in physically inaccessible areas including many mountainous regions. Regression relationships based on the feature space between the LST and the Digital Elevation Model (DEM) can be used to model the Surface Temperature Lapse Rate (NSTLR) and this can be used as an alternative to TLR in different applications (Qin et al. 2018; Romshoo et al. 2018; Zhang et al. 2018).

LST depends on a set of environmental parameters including Malbéteau et al. (2017), Firozjaei et al. (2018), and Weng et al.
(2019). Therefore, in mountainous and many natural environments, the LST- DEM feature space will be influenced by other parameters. For example, a decrease of LST was reported with the increase in elevation (Jain et al. 2008; Verhoest et al. 2012; Zhang et al. 2018). Similarly, environmental parameters including topographic conditions, solar local incident angle, and surface biophysical properties influence LST based on the LSTDEM feature space. In these situations, LST increases with an increase in elevation (Malbéteau et al. 2017; Verhoest et al. 2012). Nevertheless, using this method without considering the influence of other parameters on LST may produce errors in modeling NSTLR (Verhoest et al. 2012).

Therefore, the challenge remains in modeling NSTLR using the LST-DEM feature space from the effect of surface characteristics including biophysical and topographic characteristics on LST leading to an error in the modeling the NSTLR. The objective of this study was to investigated the impact of surface characteristics on the LST-DEM feature space for NSTLR modeling

\section{PROPOSED METHOD}

\subsection{Study area}

The Balikhli-Chay watershed in the Northwest of Iran $\left(47^{\circ} 47^{\prime}\right.$ to $48^{\circ} 05^{\prime} \mathrm{E}$ longitude and from $37^{\circ} 50^{\prime}$ to $38^{\circ} 15^{\prime} \mathrm{N}$ latitude) covers an area of $567 \mathrm{~km}^{2}$ (Figure 1). The minimum, maximum and average elevation of the watershed is 1550,4363 and 2109 meters above the mean sea level, respectively. The average slope of the watershed is $17.2 \%$. The region's dominant climate is semi-

\footnotetext{
* Corresponding author
} 
arid with an average long-term annual temperature and rainfall of $8^{\circ} \mathrm{C}$ and $360 \mathrm{~mm}$, respectively. Biophysical characteristics such as vegetation and soil moisture of the region in spatial and temporal dimensions are heterogeneous and variable. Due to mountainous conditions and sudden slope changes, this watershed has special hydrological and geomorphologic characteristics.

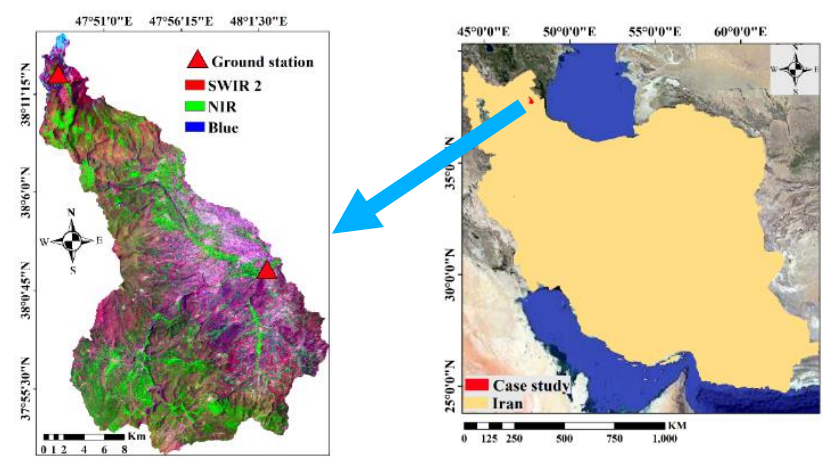

Figure 1. The study area

\subsection{Data}

In this study, meteorological and remote sensing data sets were used to model NSTLR and evaluate the performance. Landsat 8 image of the studied area with WRS_PATH= 167 and WRS ROW= 34 on 01/07/2018, 18/08/2018 and 03/09/2018 were collected and used to model LST and surface biophysical characteristics including brightness, greenness and wetness. The water vapor product (MOD07) of the MODIS sensor were used to estimate LST obtained from Landsat image. The ASTER Digital Elevation Model (GDEM) was used to model various topographical parameters including elevation, slope, and aspect. These data sets were downloaded from the United States Geological Survey website (https://earthexplorer.usgs.gov/). In addition, land use map prepared by Iranian Rangeland and Forestry was also used in this study.

\subsection{Method}

The relationship between the LST obtained from satellite images and the elevation obtained from GDEM was used to model NSTLR. The steps adopted in this study are showed in a flowchart in Figure 2. In the first step, after pre-processing of satellite images, LST and various spectral indices including Normalized Difference Built Index (NDBI), Normalized Difference Vegetation Index (NDVI) and Normalized Difference Water Index (NDWI) were calculated using reflective and thermal bands of the satellite images. Various topographical parameters including elevation, slope, and aspect were calculated using the GDEM of the study area. In the second step, the relationship between each of the parameters and the LST was investigated to determine the impact of each surface biophysical characteristics and topographic parameters on the LST. In the third step, based on the approaches presented in previous studies, the relationship between LST and elevation over the region was investigated and an NSTLR value was calculated at the regional scale. Finally, the relationship between LST and elevation at different classes of surface biophysical characteristics and topographic parameters were studied and for each class of surface characteristic, an NSTLR value was calculated.

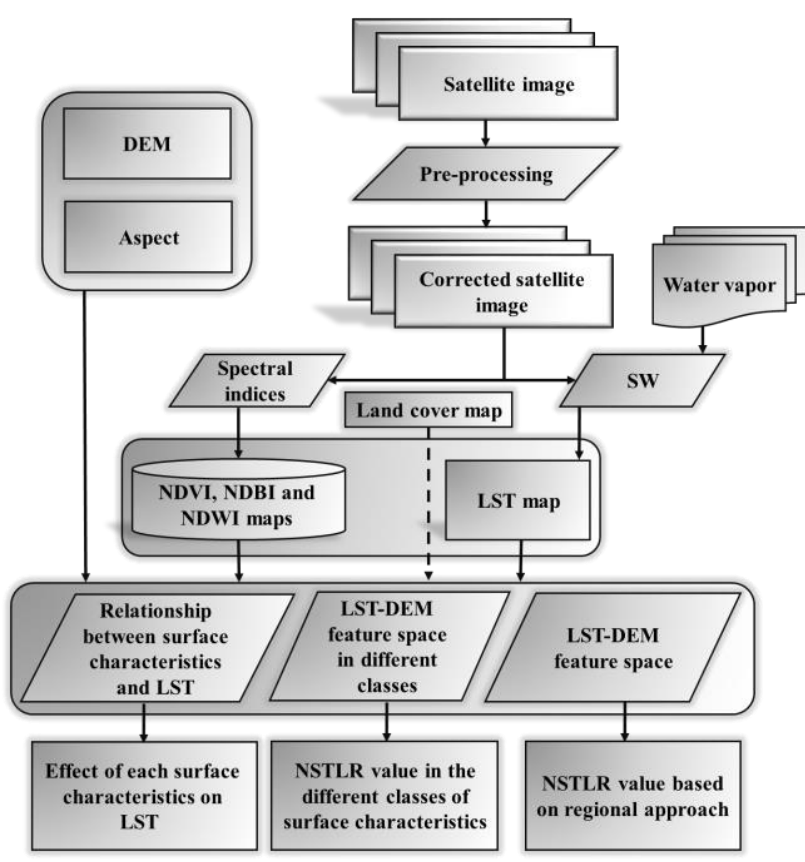

Figure 2. Flow diagram showing the analytical steps adopted in this study

\section{RESULTS}

Surface biophysical characteristics, topographical parameters and land use maps of the study area on 01/07/2018 are shown in Figure 3.

NDVI

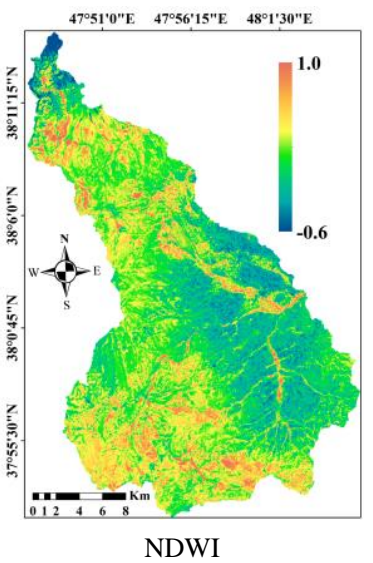

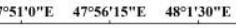

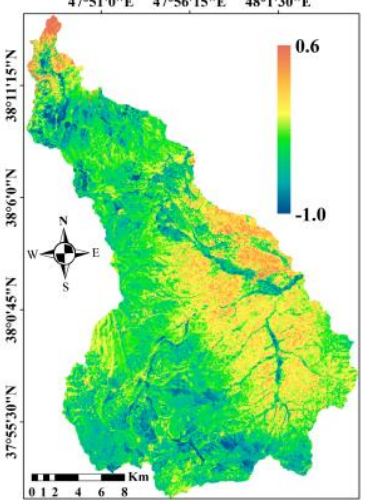

Slope (degree)
NDBI

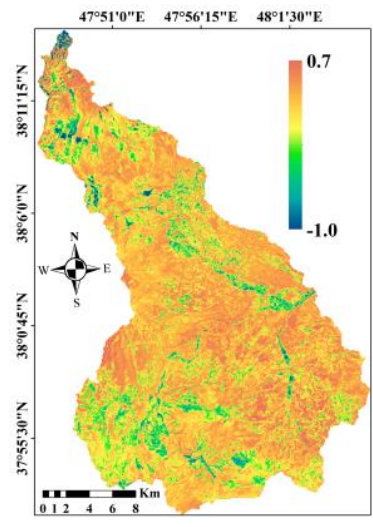

Elevation (meter) $47^{\circ} 51^{\prime} 0^{\prime \prime E} \quad 47^{\circ 5} 6^{\prime} 15^{\prime \prime} \mathrm{E} \quad 48^{\circ} 1^{\prime} 30^{\circ "} \mathrm{E}$

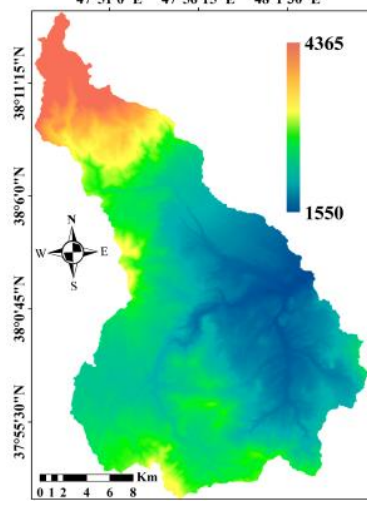

Aspect (degree) 


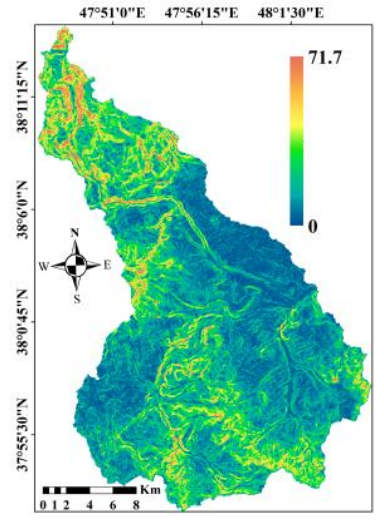

$\operatorname{LST}\left({ }^{\circ} \mathrm{C}\right)$

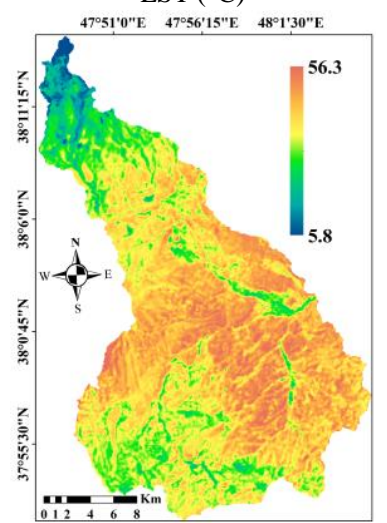

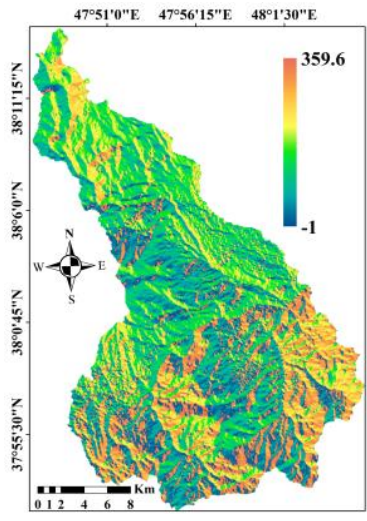

Land use

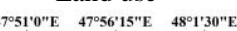

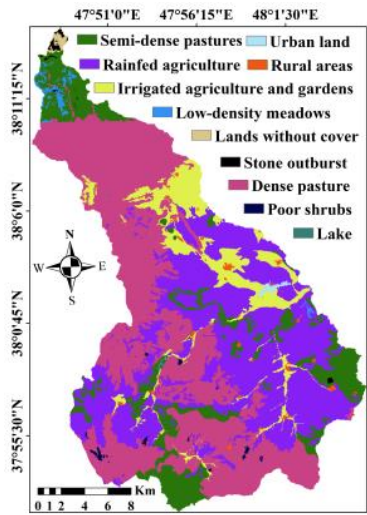

$\pi=-\mathrm{km}$
Figure 3. Maps of Surface biophysical characteristics, topographical parameters and land use of the study area on 01/07/2018.

The surface biophysical characteristics and topographical parameters of the study area are heterogeneous. The relationship between DEM and LST is inverse due to the effect of NSTLR. The LST decreased with the increase of elevation (He et al. 2018; Jain et al. 2008; Lakshmi et al. 2001; Zhang et al. 2018). The results for different dates are shown in Table 1.

\begin{tabular}{c|ccc}
\hline Date & $01 / 07 / 2018$ & $18 / 08 / 2018$ & $03 / 09 / 2018$ \\
\hline NSTLR & 8.5 & 1.5 & 2.4 \\
\hline
\end{tabular}

Table 1. NSTLR value based on LST-DEM feature space for different dates $\left({ }^{\circ} \mathrm{C} \mathrm{Km}^{-1}\right)$.

The NSTLR values of the study area varies with time (Table 4). The LST-DEM feature space is significantly affected by surface biophysical and topographical parameters such as NDBI, NDVI, NDWI and solar local incident angle (McCutchan and Fox 1986). For example, LST varied by $>15^{\circ} \mathrm{C}$ for some pixels with the same elevation range. The LST also decreased with increasing elevation in some pixels because of the surface biophysical and topographical parameters on the LST.

Due to the impact of surface characteristics on LST, the use of the LST-DEM feature space caused an error in modeling NSTLR (He et al. 2018; Verhoest et al. 2012).

The values of NSTLR in different classes of NDVI, NDBI, and NDWI are shown in Figure 4. The NSTLR at different classes of biophysical characteristics are different (Figure 4). The average determination coefficient of the studied area on 01/07/2018, $18 / 08 / 2018$ and 03/09/2018 for different classes of NDVI were $0.72,0.29$, and 0.33 , respectively, for the different classes of NDBI were $0.80,0.28$, and 0.44 , respectively and for different classes of NDWI were $0.55,0.36$ and 0.54 , respectively. The modeled NSTLR based on the LST-DEM feature space was affected by surface biophysical characteristics. In the study Verhoest et al. (2012) shown that the modeled NSTLR based on the relationship between LST and DEM for different classes of vegetation was different (Verhoest et al. 2012).

The use of NDWI, NDVI and NDBI well captured variations in moisture, vegetation and impervious. However, these indices could not delineate the differences in land cove/use types (Panah et al. 2017; Xiao and Weng 2007). Therefore, the NSTLR in the land cover classes was calculated separately and the results are shown in Figure 4. The highest and the lowest NSTLR were for lands without cover and irrigated agriculture and gardens, respectively (Figure 4).
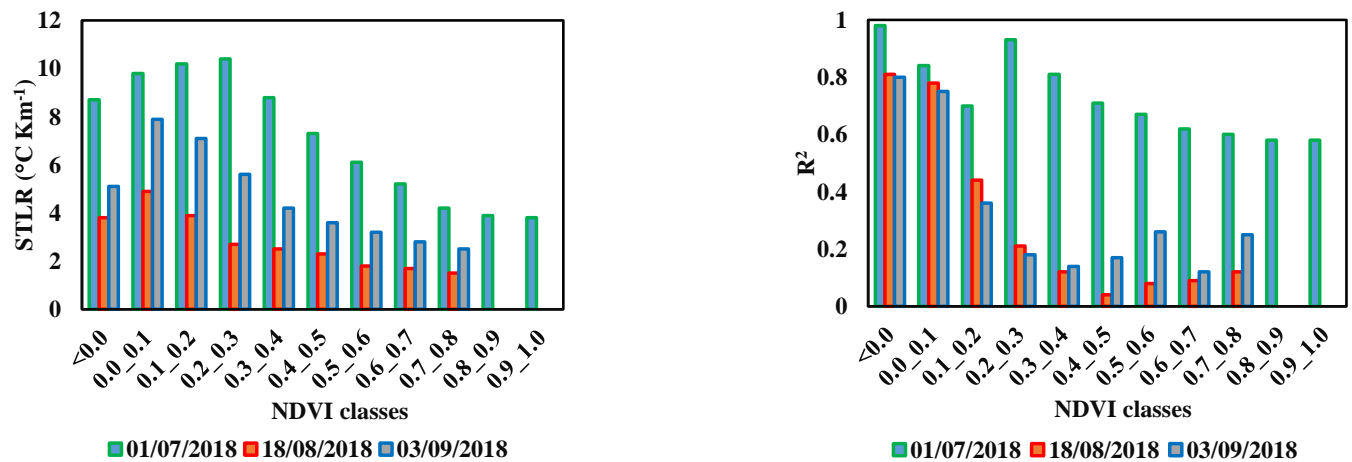

$\square 01 / 07 / 2018 \square 18 / 08 / 2018 \square 03 / 09 / 2018$ 


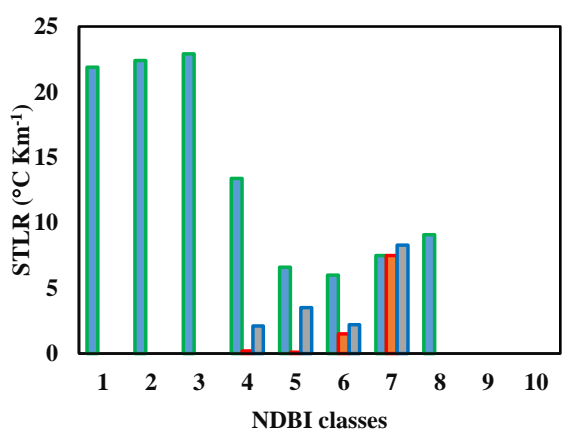

$\square 01 / 07 / 2018 \square 18 / 08 / 2018 \square 03 / 09 / 2018$

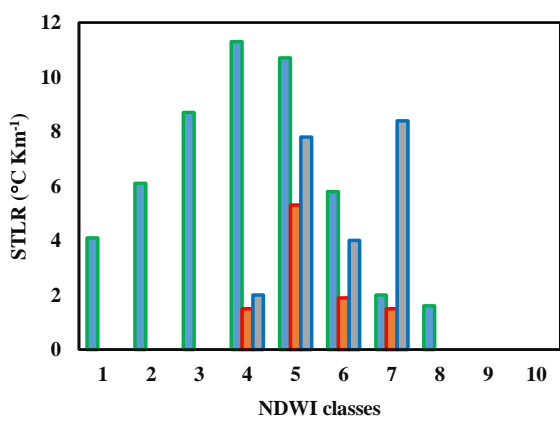

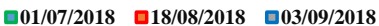

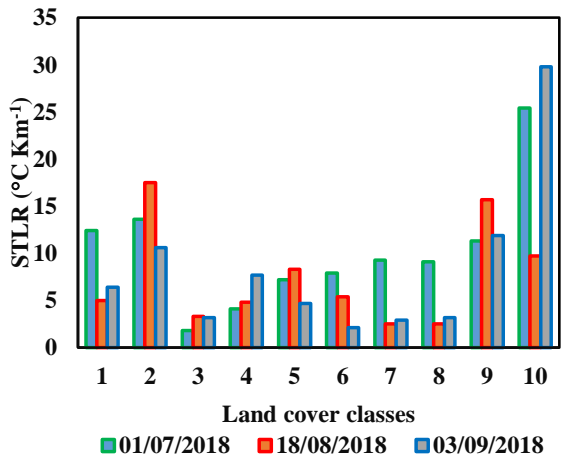

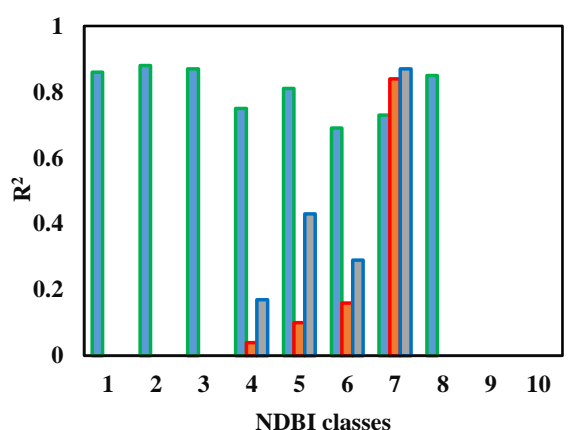

$\square 01 / 07 / 2018$ 口 18/08/2018 $\square 03 / 09 / 2018$

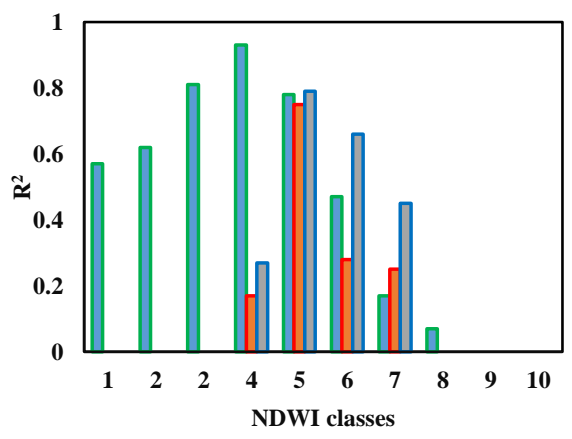

$\square 01 / 07 / 2018 \square 18 / 08 / 2018 \square 03 / 09 / 2018$

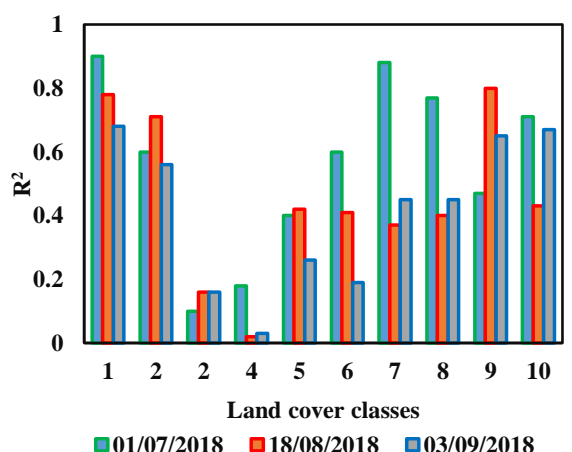

Figure 4. The values of NSTLR and $\mathrm{R}^{2}$ in different classes of NDVI, NDBI, NDWI and land use at different dates.

In addition, topographical parameters also affected LST and therefore the LST-DEM feature space. Accordingly, the NSTLR in different classes of aspects was modeled and the results are shown in Figure 5.

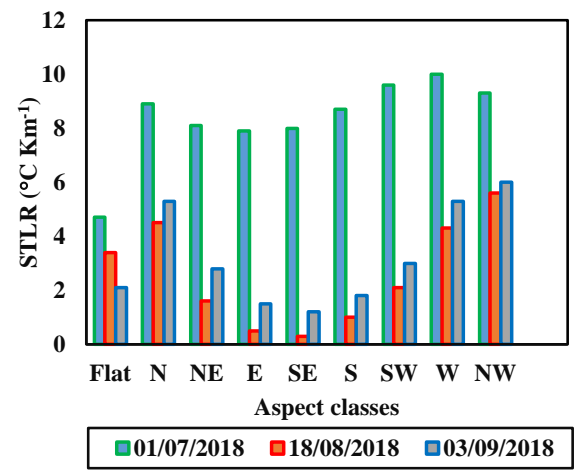

The NSTLR varied at different topographic conditions (He et al. 2018). (Liu and $\mathrm{Li} 2006$ ) also recommended addition of aspects in the modeling of the NSTLR based on the LST-DEM feature space. In this study area, the maximum and the minimum values of NSTLR were for the $\mathrm{W}$ and SW aspects, respectively.

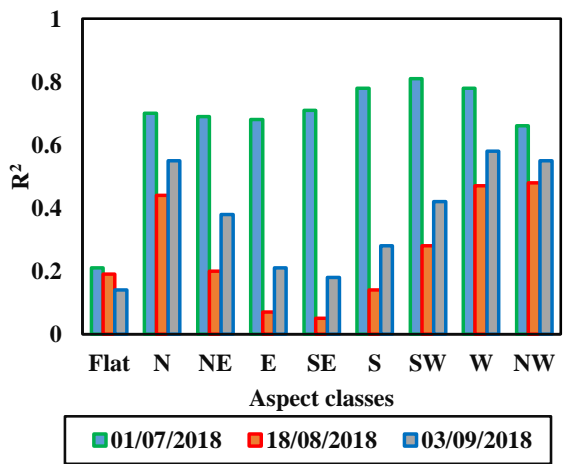

Figure 5. The NSTLR and $\mathrm{R}^{2}$ values in different classes of aspects in the study area at different dates. 


\section{CONCLUSIONS}

Increasing elevation from the mean sea level, in constant time and position, causes a decrease in the air temperature, which is called the TLR effect. Modeling of the TLR is very important in many applications. In many studies, air temperature data recorded at synoptic stations has been used for TLR modeling. However, in many mountainous regions, data from synoptic and terrestrial stations at different elevation with appropriate spatial distribution are not available. To solve this challenge in different applications, the LST-DEM feature space was used to model NSTLR. In mountainous regions, the LST-DEM feature space is influenced by surface biophysical and topographic characteristics. As a result, the use of this method, regardless of the effect of these parameters, causes the error in NSTLR modeling. The results of this study indicated that, the modeled NSTLR value based on the LST-DEM feature space for different dates, was different. Mean and standard deviation values of different surface characteristics in different dates indicated the spatial and temporal variations of the surface biophysical characteristics and solar local incident angle in the region. The value of NSTLR calculated in different topographic and biophysical conditions also varied. For future research, the use of regression and energy balance-based model for normalization of LST relative to topographic and biophysical conditions could increase the accuracy of modeling of NSTLR.

\section{REFERENCES}

Blandford, T.R., Humes, K.S., Harshburger, B.J., Moore, B.C., Walden, V.P., \& Ye, H. (2008). Seasonal and synoptic variations in near-surface air temperature lapse rates in a mountainous basin. Journal of Applied Meteorology and Climatology, 47, 249261

Danielson, E.W., Levin, J., \& Abrams, E. (2003). Meteorology. McGraw-Hill

Firozjaei, M.K., Kiavarz, M., Alavipanah, S.K., Lakes, T., \& Qureshi, S. (2018). Monitoring and forecasting heat island intensity through multi-temporal image analysis and cellular automata-Markov chain modelling: A case of Babol city, Iran. Ecological Indicators, 91, 155-170

Firozjaei, M.K., Kiavarz, M., Nematollahi, O., Karimpour Reihan, M., \& Alavipanah, S.K. (2019). An evaluation of energy balance parameters, and the relations between topographical and biophysical characteristics using the mountainous surface energy balance algorithm for land (SEBAL). International Journal of Remote Sensing, 1-31

He, J., Zhao, W., Li, A., Wen, F., \& Yu, D. (2018). The impact of the terrain effect on land surface temperature variation based on Landsat- 8 observations in mountainous areas. International Journal of Remote Sensing, 1-20

https://earthexplorer.usgs.gov/

Jain, S.K., Goswami, A., \& Saraf, A. (2008). Determination of land surface temperature and its lapse rate in the Satluj River basin using NOAA data. International Journal of Remote Sensing, 29, 3091-3103

Kattel, D.B., Yao, T., \& Panday, P.K. (2018). Near-surface air temperature lapse rate in a humid mountainous terrain on the southern slopes of the eastern Himalayas. Theoretical and applied climatology, 132, 1129-1141
Lakshmi, V., Czajkowski, K., Dubayah, R., \& Susskind, J. (2001). Land surface air temperature mapping using TOVS and AVHRR. International Journal of Remote Sensing, 22, 643-662

Li, X., Wang, L., Chen, D., Yang, K., Xue, B., \& Sun, L. (2013). Near-surface air temperature lapse rates in the mainland China during 1962-2011. Journal of Geophysical Research: Atmospheres, 118, 7505-7515

Liu, Y., \& Li, F. (2006). A preliminary approach on the land surface temperature (LST) lapse rate of mountain area using MODIS data. In, Remote Sensing and Space Technology for Multidisciplinary Research and Applications (p. 619907): International Society for Optics and Photonics

Malbéteau, Y., Merlin, O., Gascoin, S., Gastellu, J.-P., Mattar, C., Olivera-Guerra, L., Khabba, S., \& Jarlan, L. (2017). Normalizing land surface temperature data for elevation and illumination effects in mountainous areas: A case study using ASTER data over a steep-sided valley in Morocco. Remote Sensing of Environment, 189, 25-39

McCutchan, M.H., \& Fox, D.G. (1986). Effect of elevation and aspect on wind, temperature and humidity. Journal of climate and applied meteorology, 25, 1996-2013

Minder, J.R., Mote, P.W., \& Lundquist, J.D. (2010). Surface temperature lapse rates over complex terrain: Lessons from the Cascade Mountains. Journal of Geophysical Research: Atmospheres, 115

Panah, S., Mogaddam, M.K., \& Firozjaei, M.K. (2017). MONITORING SPATIOTEMPORAL CHANGES OF HEAT ISLAND IN BABOL CITY DUE TO LAND USE CHANGES. International Archives of the Photogrammetry, Remote Sensing \& Spatial Information Sciences, 42

Qin, Y., Ren, G., Zhai, T., Zhang, P., \& Wen, K. (2018). A New Methodology for Estimating the Surface Temperature Lapse Rate Based on Grid Data and Its Application in China. Remote Sensing, 10, 1617

Rolland, C. (2003). Spatial and seasonal variations of air temperature lapse rates in Alpine regions. Journal of climate, 16 , $1032-1046$

Romshoo, S.A., Rafiq, M., \& Rashid, I. (2018). Spatio-temporal variation of land surface temperature and temperature lapse rate over mountainous Kashmir Himalaya. Journal of Mountain Science, 15, 563-576

Verhoest, N.E., Peters, J., De Baets, B., De Clercq, E.M., \& Ducheyne, E. (2012). Influence of topographic normalization on the vegetation index-surface temperature relationship. Journal of Applied Remote Sensing, 6, 063518

Weng, Q., Firozjaei, M.K., Kiavarz, M., Alavipanah, S.K., \& Hamzeh, S. (2019). Normalizing land surface temperature for environmental parameters in mountainous and urban areas of a cold semi-arid climate. Science of the Total Environment, 650, $515-529$

Xiao, H., \& Weng, Q. (2007). The impact of land use and land cover changes on land surface temperature in a karst area of China. Journal of environmental management, 85, 245-257

Zhang, H., Zhang, F., Zhang, G., Che, T., \& Yan, W. (2018). How accurately can the air temperature lapse rate over the Tibetan Plateau be estimated from MODIS LSTs? Journal of Geophysical Research: Atmospheres, 123, 3943-3960 